\title{
Use of in-situ dynamic measurements to calibrate analytical models of RC-elevated water tanks
}

\author{
H.M. Lopes and C.S. Oliveira* \\ Instituto Superior Técnico, Lisbon, Portugal
}

\begin{abstract}
Before establishing the priority settings for the reduction of seismic risk of water supply infrastructures, it is necessary to understand the dynamic behavior of elevated water tanks, which are components of those infrastructures. Among other information, the main frequencies of vibration of these structures must be estimated and the analytical models used in their analysis and design should reproduce the frequency values obtained by in-situ dynamic tests. This work focuses exclusively on reinforced concrete (RC) elevated water tanks $\left(200-750 \mathrm{~m}^{3}\right.$ of water at heights of $30-40 \mathrm{~m}$ ), which are very common structures in the water supply systems in Portugal since the mid $\mathrm{XX}^{\text {th }}$ century. This type of structures can also be seen in many regions around the world.

First, a nationwide survey was conducted to determine the most common typologies in the country in terms of structural layout. Second, an in-situ campaign using ambient vibration as input was performed for a group of selected structures to determine the main frequencies of vibration and to identify modal shapes and damping values. Third, a finite element model of several different typologies was developed using the water simply as a concentrated mass at the top; the elastic properties of the model of the structure including the foundation were calibrated, so that the frequencies of various mode shapes obtained by the analytical model would match the frequencies of the real structure. Finally, an expression was derived to estimate the fundamental frequency of a group of elevated water tank typologies based on the total mass at the top of the supporting structure, which include the water, the global lateral stiffness, and the height of the tank.

This study, providing important information on the frequencies of vibration of RC-elevated water tanks, contributes in a definite way to the analysis and design of such water tanks.
\end{abstract}

Keywords: Dynamic analysis, RC elevated water tanks, identification of frequencies, analytical modeling

\section{Introduction}

The determination of the seismic vulnerability of water supply networks is considered a national priority [1] in reducing the seismic impacts in Portugal. Specifically, this paper addresses the seismic vulnerability of reinforced concrete (RC)-elevated water tanks. When failed, this structure may become a constraint on the functionality of the existing water supply network in several municipalities throughout the country, especially in areas such as the Metropolitan Area of Lisbon and the Algarve, where the seismic hazard is moderate to strong [2,3]. The objectives of the paper are: (i) to recognize the most common typologies in the country and select a group of 44 structures to be characterized; ${ }^{1}$ (ii) to perform an $i n$-situ campaign under ambient vibration noise to identify the main frequencies of vibration for all of these structures and to determine the modal shapes and damping values in one case; (iii) to perform a linear finite element analysis of several structures and calibrate their mechanical properties to reproduce their dynamic behavior properly under low amplitude motion; and (iv) to establish correlations between measured

*Corresponding author: C.S. Oliveira, Instituto Superior Técnico, Av. Rovisco Pais, 1049-001 Lisbon, Portugal. E-mail: csoliv@civil. ist.utl.pt.

${ }^{1}$ We have seen that the typologies observed in Portugal do exist in many regions of the world, and they are still important equipments for water supply networks. 
frequencies and the main geometric and material properties of the water tanks under study to make an overall static and dynamic characterization of these types of structures. For a selected group of cases, it was possible to obtain an expression to estimate the fundamental frequency of an elevated water tank based on the height of the tank, the total mass at the top of the stack and the global lateral stiffness.

As a continuation of the present study, ongoing research aims at determining the seismic vulnerability of the most typical RC-elevated water tanks based on non-linear pushover analysis [4].

\subsection{Brief account of the RC-elevated water tank typologies in Portugal}

The existing RC-elevated water tanks that were built 50 to 60 years ago in Portugal can be approximately grouped into the following types distinguishable by basic parameters including tank height and capacity, design/construction epoch and material. (In this study, only structures with identifiable main sub-types or classes were analyzed.) (1) Hintze type, ${ }^{2}$ a RC 3-D frame formed by columns at a peripheral ring connected by ring beams at several heights; ${ }^{3}$ (2) RC circular slender shaft with hollow section: - shaft diameter - thickness of the wall shaft; (3) RC double structure, a combination of type (1) and type (2); (4) RC cylindrical shell with strong radial columns; (5) special cases. Case (1) can be sub-divided into three classes. In (1a), the outer RC frame is filled with a wall in masonry, in (1b) the filling is concrete shell and in (1c) there are slabs at the beam levels. To complete the classification, the foundation type and the geological and geotechnical conditions were also examined. In Fig. 1, examples of the main typologies mentioned above are presented.

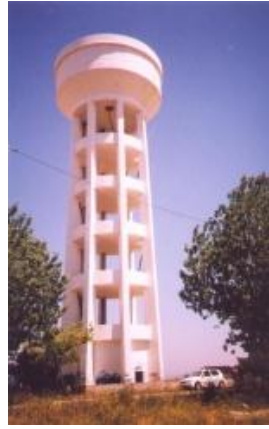

1-RC Hintze

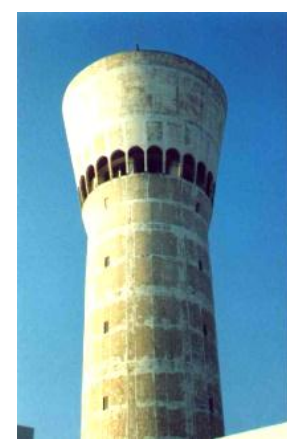

1a-RC Hintze with infilled masonry

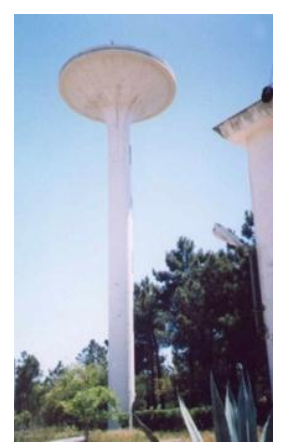

2-RC circular shaft

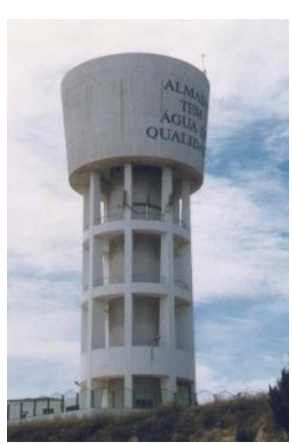

3-RC double structure

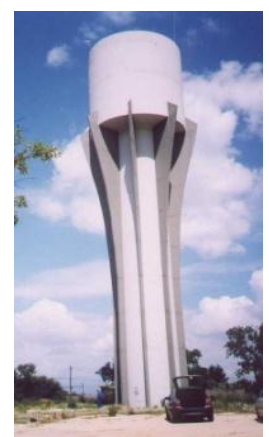

4-RC shell with strong columns

Fig. 1. Main typologies of elevated water tanks.

Based on the structural types presented, the major characteristics and descriptions of 44 different water tanks located mostly in the southern bank of the Tagus River near Lisbon and many tanks in Algarve have been summarized in Table 1. Similar typologies can be found in other areas of the Portuguese territories, both in the Continent and in the Azores. In addition to the name and city of each structure, Table 1 presents the typology classes, the tank capacity, the percent of water volume filling the tank at the time of the in-situ testing, the height from the ground level to the base of the tank (stack-shaft or frame), the average external diameter and the frequencies determined from in-situ testing. A reference is also made to the structures that were the object of analytical studies on frequencies and on seismic vulnerability.

The database from which the parameters in Table 1 were taken contains more detailed information on the geometric characterization of the structure. This information was obtained from the design drawings (if available) or from direct measurements of the main structural elements.

\footnotetext{
${ }^{2}$ There is no clear definition for a Hintze structure: the name refers to the spatial frame or to the type of tank. This is also referred to in the literature as Intze structures.

${ }^{3}$ A more detailed characterization would include information on: - number of columns, - shaft diameter, - number of levels of beams, number of levels of slabs, - openings filled or not with masonry.
} 
Table 1

Geometric characterization and first in-situ frequencies of various types of elevated water tanks

\begin{tabular}{|c|c|c|c|c|c|c|c|c|c|c|c|c|}
\hline Name & Typology & capacity & water level & height* & $\varphi$ ext & 1st freq. & 2nd freq. & 3rd freq. & 4th freq. & 1st torsio & 2nd torsion & Comput. \\
\hline & & (m3) & \begin{tabular}{|l|}
$\%$ \\
\end{tabular} & $(\mathrm{~m})$ & $(\mathrm{m})$ & $(\mathrm{Hz})$ & $(\mathrm{Hz})$ & $(\mathrm{Hz})$ & $(\mathrm{Hz})$ & $(\mathrm{Hz})$ & $(\mathrm{Hz})$ & analysis \\
\hline Abelheira - Quarteira & 1 & 150 & 100 & 25 & 6.5 & 1.95 & 4 & 9 & & 2 & & \\
\hline Alto Cavaquinho - Seixal & 4 & 200 & 100 & 20 & 3.9 & 1.25 & & 9.8 & & 6.38 & & freq \\
\hline Alto Lazarim - Almada & 2 & 430 & 70 & 22 & 4.8 & 1.86 & & & & 6.98 & & \\
\hline Alto Pacheco - Portimão & $1 \mathrm{a}$ & 500 & 100 & 28.6 & 8.7 & 1.56 & 8.2 & 17 & & 5.2 & & \\
\hline Alto Rodes - Faro & $1 \mathrm{~b}$ & 1000 & 15 & 29.5 & 6.0 & 1.07 & 5.8 & & & 2 & & \\
\hline Amoreiras - Portimão & $1 \mathrm{a}$ & 500 & 100 & 24.6 & 8.7 & 1.76 & 9.8 & 17 & 23 & 5.8 & & \\
\hline Barrosa - Benavente & 2 & 320 & 50 & 18 & 4.0 & 2.1 & 11.2 & & & & & \\
\hline Base Lajes - Terceira Açores & 1 & 250 & 100 & 14 & 8.0 & 1.03 & 7.1 & & & 2.15 & & vulnerab \\
\hline Belverde - Seixal & 2 & 90 & 80 & 24 & 2.0 & 0.49 & 4.5 & 12 & & & & freq \& vulnerab \\
\hline Bemposta - Portimão & $1 \mathrm{a}$ & 200 & 100 & 22 & 6.1 & 1.95 & 11.3 & 32 & & 6.6 & & \\
\hline Benavente Novo & 3 & 750 & 100 & 19.5 & 3.0 & 1.27 & 8.3 & & & 2.9 & 10.9 & \\
\hline Benavente Velho & 1 & 250 & 70 & 18 & 6.5 & 1.6 & 9.9 & 12.4 & 19.2 & 2.4 & & \\
\hline Boavista - Portimão & $1 \mathrm{a}$ & 500 & 100 & 32 & 8.7 & 1.37 & 7 & 14 & 19 & 4 & & \\
\hline Caparica - Almada & 1 & 100 & 100 & 16 & 5.0 & 1.37 & & & & & & \\
\hline Casal Marco - Seixal & 4 & 200 & 25 & 20 & 3.9 & 1.46 & 3.6 & 11.3 & & 6.54 & & freq \\
\hline Cassapo - Almada & $1 \mathrm{a}$ & 500 & 60 & 24 & 7.8 & 1.95 & 11.3 & 16 & & 8.7 & & \\
\hline Centro - Aveiro & $1 \mathrm{a}$ & 750 & 100 & 27 & 10.6 & 2.53 & & & & 8.9 & & \\
\hline Cerro de Águia - Albufeira & $1 \mathrm{a}$ & 300 & 100 & 23 & 7.8 & 2.15 & 11.4 & & & & & \\
\hline Chão das Donas - Portimão & $1 \mathrm{a}$ & 500 & 100 & 30 & 8.7 & 1.56 & 8.5 & 16.9 & 23 & 5.2 & & \\
\hline Corroios - Seixal & $1 \mathrm{a}$ & 300 & 0 & 17 & 5.0 & 2.64 & 14.2 & & & 11.3 & & \\
\hline Depósito Univ. - Aveiro & 5 & 100 & 50 & 30 & 5.0 & 0.78 & 4.7 & & & & & freq \\
\hline Estrelinha - Almada & 2 & 125 & 100 & 13 & 4.4 & 1.76 & 10 & 11.7 & & 2.2 & & \\
\hline Feijó - Almada & 3 & 750 & 30 & 26 & 10.1 & 1.8 & 7 & & & & & \\
\hline Feijó Velho - Almada & 1 & 100 & 0 & 11 & 6.0 & 1.66 & 8 & 8.9 & 9.3 & 2.06 & & \\
\hline Fernão Ferro Casal Sapo - Seixal & 4 & 700 & 50 & 12 & 9.9 & 3.71 & 5.1 & 11.9 & & 10.9 & & \\
\hline Grândola & $1 \mathrm{~b}$ & 750 & 100 & 29.5 & 8.0 & 1.56 & 8.3 & 18.7 & 28.5 & 5.5 & 11.8 & \\
\hline Laranjeiro - Almada & 4 & 500 & 80 & 24 & 8.0 & 1.3 & 3.1 & 9 & & 4.8 & & \\
\hline Mexilhoeira Grande & $1 \mathrm{a}$ & 300 & 100 & 12 & 7.8 & 4.2 & 19 & & & 9.8 & & \\
\hline Miratejo - Seixal & 1 & 500 & & 26 & 8.2 & 0.96 & 4.3 & 8.3 & 11.2 & 1.36 & 5.6 & modes \& resp \\
\hline Mte Caparica (velho) Almada & 1 & 100 & 0 & 11 & 5.7 & 1.8 & 4 & 8 & & 2.1 & & \\
\hline Porches - Porches & $1 \mathrm{~b}$ & 200 & 80 & 11 & 4.0 & 3 & & 13.7 & & 9 & & \\
\hline Praia da Luz - Lagos & 2 & 100 & 100 & 19 & 2.4 & 0.98 & & 8.6 & 13.7 & 6.4 & 9.5 & \\
\hline R4 - Vila Moura & 4 & 400 & 100 & 18 & 6.0 & 2.34 & & & & & 5.8 & \\
\hline Radio Naval - Horta & 1 & 10 & 0 & 9.5 & 3.0 & 1.46 & 10.9 & & & 2.5 & & freq \\
\hline Raposo - Almada & 5 & 1000 & 50 & 25 & 18.0 & 2.44 & & & & 3 & & \\
\hline Samora Correia & 2 & 500 & 100 & 31 & 4.0 & 0.68 & 4.9 & 14.1 & & 7.9 & & \\
\hline São Jacinto - Aveiro & $1 \mathrm{a}$ & 350 & 80 & 15 & 7.6 & 1.95 & & & & 5.2 & & \\
\hline Sines & 4 & 250 & 0 & 18.8 & 6.6 & 1.82 & 5.3 & & 14.4 & & 2.48 & \\
\hline Silval - Oliveirinha-Aveiro & $1 \mathrm{a}$ & 500 & 100 & 27 & 8.7 & 1.66 & 8.5 & 13.7 & & 4.8 & & \\
\hline Sta. Comba Dão & $1 \mathrm{a}$ & 500 & 100 & 25.3 & 9.0 & 1.66 & 8.3 & 17.8 & 23.6 & 4.45 & 15.1 & \\
\hline Sta. Marta - Seixal & 2 & 350 & 80 & 32 & 4.0 & 0.6 & 5.1 & & & & & freq \\
\hline Sto. António - Faro & 2 & 200 & 0 & 38 & 5.0 & 0.98 & 5 & & & 2.2 & & \\
\hline $\mathrm{St}^{\mathrm{o}}$. Estevão & 2 & 150 & 100 & 16 & 3.3 & 1.66 & 7.5 & 11.7 & & 2.5 & & \\
\hline Torre Marinha - Seixal & 1c & 500 & 60 & 26 & 8.2 & 1.07 & 4.1 & & & & 6.8 & freq \\
\hline
\end{tabular}

${ }^{*}$ from ground to base of tank

1-Hintze; 1a-Hintze+Masonry infill; 1b-Hintze+RC inf; 1c-Hintze+slab;2-RC circ shaft; 3- Double struct; 4-RC shell+strong pillars; 5-special

\subsection{Damage observed in past earthquakes}

Even though only RC-elevated tanks built the past 50 years in Portugal were analyzed, these structures were built in many different regions around the world following the appropriate codes and standards developed not only in countries with advanced technologies but also in countries with long traditions of using these types of structures. France, USA, Turkey, and Haiti are just a few countries where elevated RC water tanks are in full function.

Past earthquakes are full of examples of cases showing the safe and unsafe behavior of elevated RC tanks during shaking. The most common problems in RC Hintze typologies are the cracking of the beams around the beam-column connections, as seen in the Lajes water tank in Terceira Island (Azores) during the 1980 earthquake. Here the beam cracks appear at peak ground acceleration (PGA) of approximately $30 \mathrm{~cm} / \mathrm{s}^{2}$ [5]. A similar occurrence was observed in Perú [6] during the 1996 earthquake (Fig. 2a). For cylindrical shafts, the main problem is the rotation of the foundation [7], as occurred in Iran during the 1990 earthquake (Fig. 2b). Complete collapses of large water tanks were also observed for the same earthquake. Other examples include the Friuli 1976 [8], Bhuj 2001 [9], and Haiti 2010 [10] earthquakes. However, in many other earthquakes, these structures have behaved quite well in contrast to the great destruction observed in the surrounding areas, such as in Sichuan (China) [11] during the 2008 earthquake. 


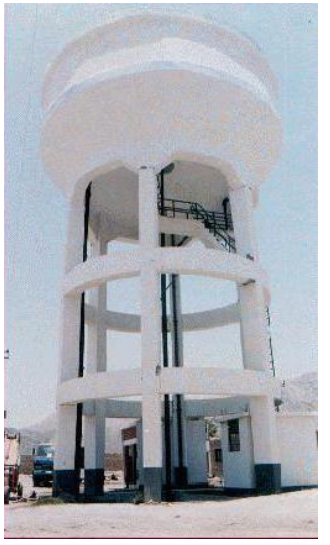

(a) City of Nasca (Peru)
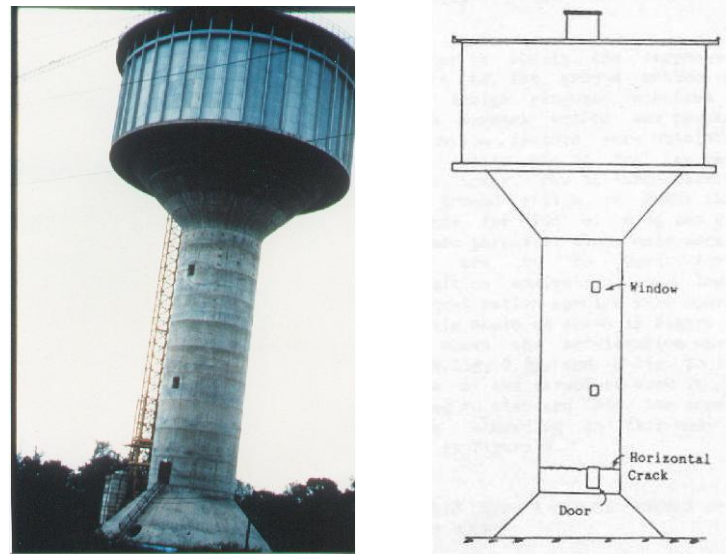

(b) City of Manjil Roudbar (Iran); tilted tower

Fig. 2. Damage inflicted to: (a) Hintze-type elevated water tanks, (b) cylindrical shaft.

The analysis and design of elevated water tanks under seismic action is a rather sophisticated topic due to the large mass of water positioned at a high location. This water, depending on the shape of the tank, oscillates separately from the tank during the transmitted moderate to strong motion and causes sloshing effects. The sloshing phenomenon [12] and the determination of ductility of inverted pendulum structures have been investigated and are considered in the codes of practice for the last 25 years [13-19].

Rai [9,20,21] has studied RC shaft-elevated water tanks affected by strong events, proposing techniques for their rehabilitation and recommending alterations on world codes to significantly reduce the ductility of these types of structures. These recommendations follow the same design philosophy of EC-8 [18], ACI [16], IBC [17] and IITK-GSDMA [19], among other codes.

\section{Frequencies of vibration from in-situ measurements}

In-situ dynamic measurements similar to the ones described herein were already made for Hintze-type tanks by Chandrasekaran and Krishna [22] in the mid 1960s, and their results do not differ significantly from those presented below. Boyce [23] also made in-situ tests to verify the influence of water level in measured frequencies and the sloshing effect; both effects are considered in modern codes. In the present work, no sloshing effect is considered because only low amplitude motion is analyzed. Nevertheless, the water level is very important due to its additional weight.

A series of in-situ ambient vibration tests were performed in different types of the 44 structures mentioned above to determine the frequency and modes of vibration.

This technique was chosen instead of other excitation sources because it has been applied in many different situations; for flexible structures, such as elevated water tanks, the results are very robust [24]. The main idea of using ambient vibration tests to determine the dynamic characteristics of a structure is essentially based on the principle that this vibration acts at the foundation level as "white noise" being filtered by the structure along the height. The measured signal is the vibration caused by wind, traffic and water pumping. In this case, (human) walking was also used as the source of noise exciting the lower modes of vibration.

Therefore, the input signal is amplified at the natural frequencies of these structures at locations where modal shapes exhibit higher expression. By placing instrumentation at several locations and recording the response simultaneously, it is possible to identify both the frequencies and the corresponding mode shapes [24]. However, for slender structures, only the response measured at the top is necessary to determine the fundamental frequencies and the frequencies of several higher modes. The results from ambient vibration tests compare very well with those from 
alternative techniques, such as the results from earthquake ground motion recorded by permanent monitoring networks [24]. In this study, the frequencies were identified using only one accelerometric high-resolution station with three components. For most of the 44 water tanks, it was possible to obtain the frequencies of the first five modal shapes. In one case, three instruments with common timing were used to determine the modal shapes and damping ratios.

In Fig. 3a, the periods of vibration ( $\mathrm{sec}$ ) of different modes were plotted as a function of height (m), and the corresponding regression lines were plotted for typology $\mathbf{1 a}$ (a select subset of Hintze tanks with masonry infill) in Fig. $3 \mathrm{~b}$ shows similar results for all structures. One observes that, for type 1a water tanks, the scatter is low. The frequency of the 2 nd mode of translation is 5.5 times larger than the frequency of the first mode, ${ }^{4}$ while the frequency in the torsion mode is only 3.8 times larger. Overall, (Fig. 3b) the results are very scattered; however, the general trend is very similar to the trend seen in Fig. $3 \mathrm{a}$.

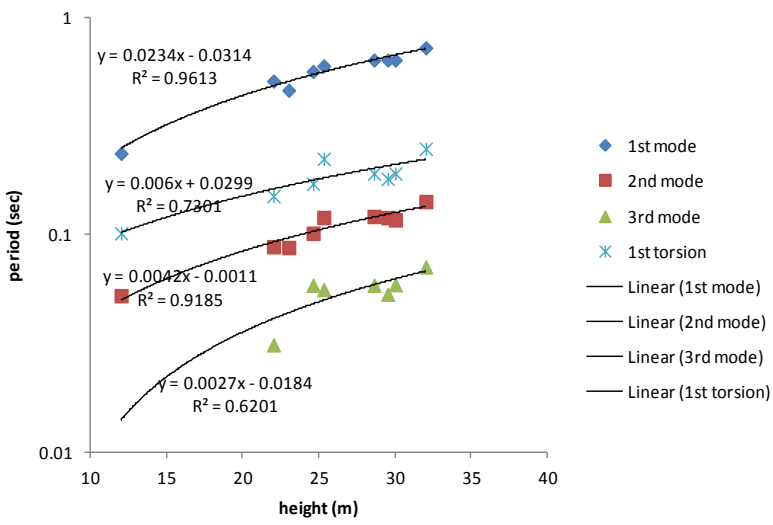

(a)

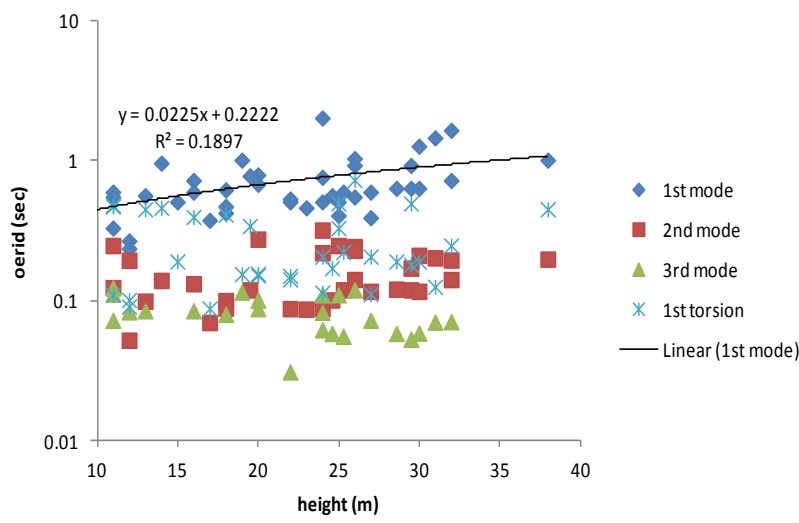

(b)

Fig. 3. Correlation of vibration period (y) with tank height (x) for different modes: a) Hintze type 1a; b) all types.

The contents of Fig. 3 (for frequencies) are replotted in Fig. 4a but only for the 1st mode for all types; this is to show the great uncertainty in the fitting process if all data are assembled together. The scattering is very high, meaning that more variables should be considered in the fitting process for the results to have any practical usage. For example, if the data are grouped by typologies, the correlation is much higher, as seen in Fig. 4b where linear fitting was performed only for the cases with more data points.

As mentioned in the beginning of this section, in-situ dynamic measurements for the first frequency were made in India for Hintze-type tanks (typology 1) by Chandrasekaran and Krishna [22]. Figure 5 compares their measured frequencies and the frequencies for this work (as in Fig. 4b). The tendencies are similar, but the Indian tanks show lower frequencies and slightly larger dispersion; this phenomenon could be a result of differently defined tank height. Damping in both experiments are identical.

\section{Modeling the structure - linear analysis}

In this section, numerical modeling was performed using the finite element method for six of the structures identified in Table 1. Two structures were the Hintze-type with slabs (Type 1c); two were circular-shaft types (Type 2 ) and two were structures with shells and strong columns (Type 4). To illustrate the modeling process, the first structure in Fig. 1 (the Miratejo water tank) is described in detail.

\footnotetext{
${ }^{4}$ Each frequency refers only to one direction of the horizontal plan because these structures are essentially symmetric. The mode in the orthogonal direction has the same frequency up to the second digit.
} 


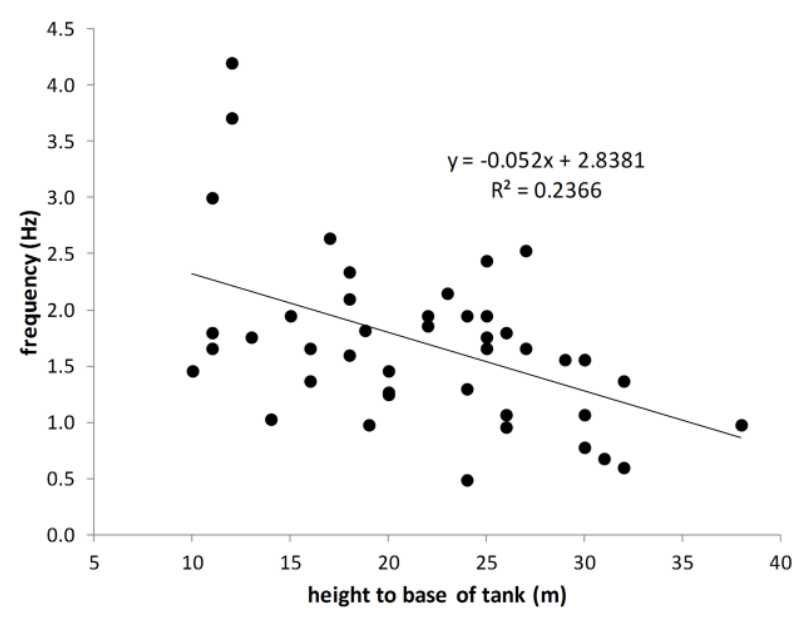

(a)

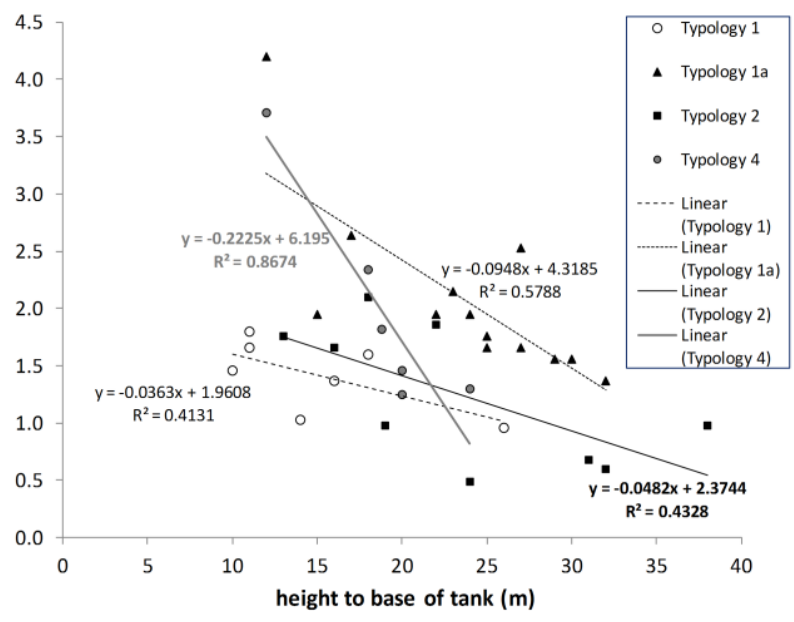

(b)

Fig. 4. Correlation of vibration frequency with tank height for the first mode: a) for all types; b) sorted by more significant typologies.

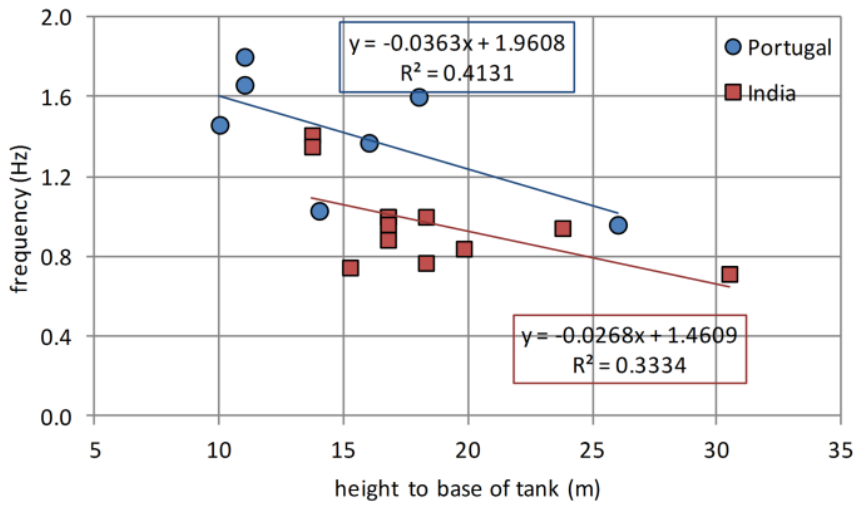

Fig. 5. Comparison between in-situ measurements in India and Portugal for typology 1 (frequency of 1 st mode).

This RC Hintze-type tank, built in the 1970s, has a total height of $36 \mathrm{~m}$ and consists of a space frame with eight 6-story vertical columns supporting $0.15 \mathrm{~m}$-thick slabs with peripheral beams and tank at the top, as shown in Fig. 1a; the model of the structure is shown in Fig. 5a. The columns are arranged in a circle with a diameter of $8.2 \mathrm{~m}$, and the cross section of the columns varies linearly from $1.527 \mathrm{~m}$ at the base to $0.767 \mathrm{~m}$ at the top (radial dimension); the width of the columns (from top to bottom) is a constant $0.60 \mathrm{~m}$. The height of the beams is constant on all floors $(0.27 \mathrm{~m})$, and their widths vary from $0.68 \mathrm{~m}$ on the $1 \mathrm{st}$ floor to $0.41 \mathrm{~m}$ on the 5 th floor. The tank has a capacity of $500 \mathrm{~m}^{3}$. The foundation of the tank at the ground floor consists of a ring beam with a base of $2.5 \mathrm{~m}$ width, an external diameter of $8.2 \mathrm{~m}$, and a height of $1.2 \mathrm{~m}$, supporting the columns. The bottom of the shaft between the ground level and the first floor is enclosed by a wall of $0.26 \mathrm{~m}$-thick brick masonry. The materials used to construct the tank were C20/25 and A400 NR. The foundation in the Holocene consists of a thick, dense, and well-compacted sand with a deformation modulus $\mathrm{E}$ of $106 \mathrm{MPa}$.

In all 6 cases studied, the design for seismic loads followed the seismic codes in use at the time of construction, which corresponded to the RSCS code until 1961 [25], the RSEP code until 1985 [26] and the RSA code [2] since then. The Miratejo tank in the present study was designed according to RSEP.

The numerical linear model was constructed using a finite element program "SAP2000 ${ }^{\circledR ”}$ [27] as follows: Columns were simulated such that the cross section varies linearly with height. Beams were simulated by bar el- 
ements with a constant cross section. Low walls and slabs were simulated by the shell elements that are $0.15 \mathrm{~m}$ and $0.10 \mathrm{~m}$ thick, respectively. The ring foundation beam was simulated by bar elements. The interaction between the structure and the soil was simulated using springs with a stiffness of approximately $290 \mathrm{MN} / \mathrm{m}$. Masonry walls were simulated by the shell elements with an elastic modulus of $8 \mathrm{GPa}$ (the wall thickness is $0.26 \mathrm{~m}$ ). The tank was simulated as a point mass located at the center of mass of the tank (255.97 ton) plus the mass of the water at the time of measurement (122.5 tons). This mass, considered as a concentrated translational mass with a polar moment of inertia (Mpi) in three directions (Mpix, $\mathrm{y}=6198.85$ ton. $\mathrm{m}^{2}, \mathrm{Mpiz}=8696.64$ ton. $\mathrm{m}^{2}$ ), was connected to the central top node of the structure by a rigid lintel.

The other structures were modeled in a similar way using bar and shell elements.

In Fig. 6, the first 5 frequencies of the structures determined analytically and by in-situ testing are compared. These frequencies correspond to the $\mathrm{x}$ and $\mathrm{y}$ directions and are equal by pairs due to the radial symmetry of the structures. For the 6 cases studied, the torsion mode ( $T$ ) fits between the first and the second pairs, corresponding, to the 1 st and 2 nd modes in each horizontal direction, respectively. This was also the criterion taken into account in setting up Table 1, in which only one horizontal direction was considered.
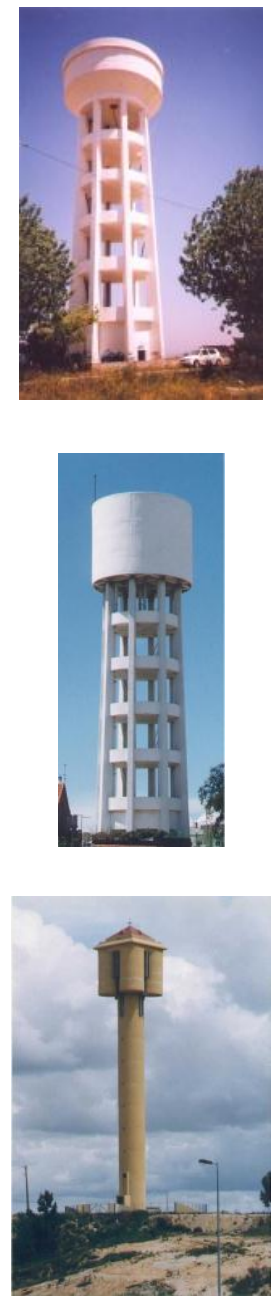

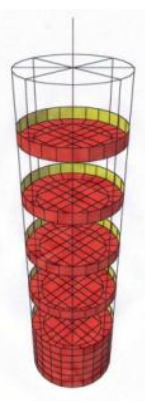

\begin{tabular}{|c|c|c|}
\hline Modes & $\begin{array}{c}\text { Analytical } \\
\mathrm{f}(\mathrm{Hz})\end{array}$ & $\begin{array}{c}\text { in-situ Testing } \\
\mathrm{f}(\mathrm{Hz})\end{array}$ \\
\hline $\mathbf{1 X}$ & 0.96 & 0.96 \\
$\mathbf{1} \mathrm{Y}$ & 0.96 & 0.96 \\
$\mathbf{T}$ & 1.30 & 1.36 \\
$\mathbf{2 X}$ & 4.05 & 4.32 \\
$\mathbf{2 Y}$ & 4.05 & 4.32 \\
\hline
\end{tabular}

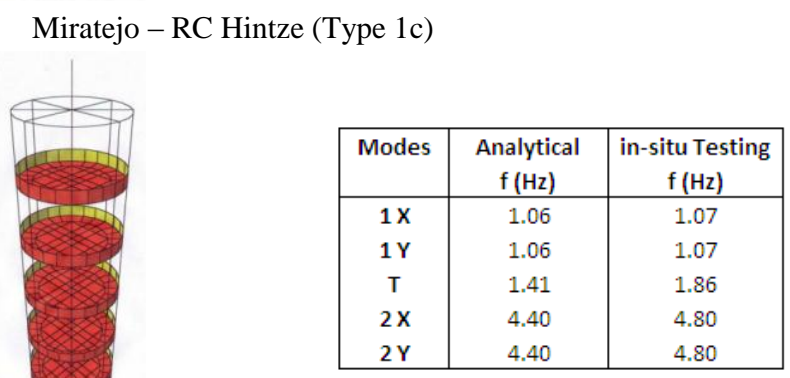

Torre da Marinha - RC Hintze (Type 1c)

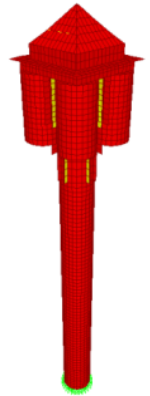

\begin{tabular}{|c|c|c|}
\hline Modes & $\begin{array}{c}\text { Analytical } \\
\mathrm{f}(\mathrm{Hz})\end{array}$ & $\begin{array}{c}\text { in-situ Testing } \\
\mathrm{f}(\mathrm{Hz})\end{array}$ \\
\hline $\mathbf{1 X}$ & 0.57 & 0.60 \\
$\mathbf{1} \mathrm{Y}$ & 0.57 & 0.60 \\
$\mathbf{T}$ & 3.78 & - \\
$\mathbf{2 X}$ & 5.24 & 5.08 \\
$\mathbf{2 Y}$ & 5.24 & 5.08 \\
\hline
\end{tabular}

Santa Marta - RC circular shaft (Type 2) 

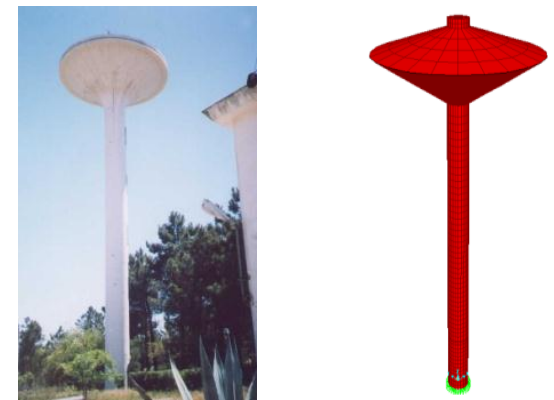

\begin{tabular}{|c|c|c|}
\hline Modes & $\begin{array}{c}\text { Analytical } \\
\mathrm{f}(\mathrm{Hz})\end{array}$ & $\begin{array}{c}\text { in-situ Testing } \\
\mathrm{f}(\mathrm{Hz})\end{array}$ \\
\hline $\mathbf{1 X}$ & 0.49 & 0.49 \\
$\mathbf{1 Y}$ & 0.49 & 0.49 \\
$\mathrm{~T}$ & 2.72 & - \\
$2 \mathrm{X}$ & 5.04 & 4.50 \\
$\mathbf{2 Y}$ & 5.04 & 4.50 \\
\hline
\end{tabular}

Belverde - RC circular shaft (Type 2)
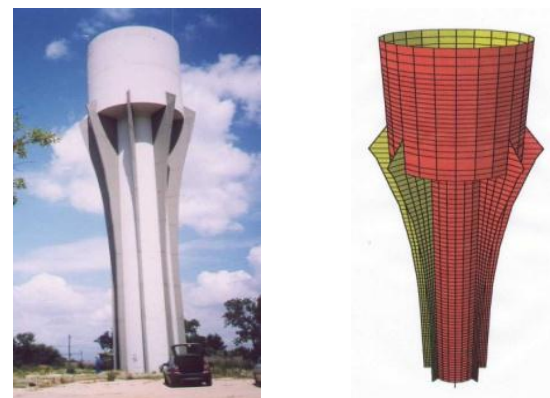

\begin{tabular}{|c|c|c|}
\hline Modes & $\begin{array}{c}\text { Analytical } \\
\mathbf{f}(\mathrm{Hz})\end{array}$ & $\begin{array}{c}\text { in-situ Testing } \\
\mathbf{f}(\mathrm{Hz})\end{array}$ \\
\hline $\mathbf{1 X}$ & 1.51 & 1.46 \\
$\mathbf{1} \mathbf{Y}$ & 1.51 & 1.46 \\
$\mathbf{T}$ & 5.96 & 6.54 \\
$\mathbf{2 X}$ & 12.31 & 11.30 \\
$\mathbf{2} \mathbf{Y}$ & 12.31 & 11.30 \\
\hline
\end{tabular}

Casal do Marco - RC shell with strong columns (Type 4)
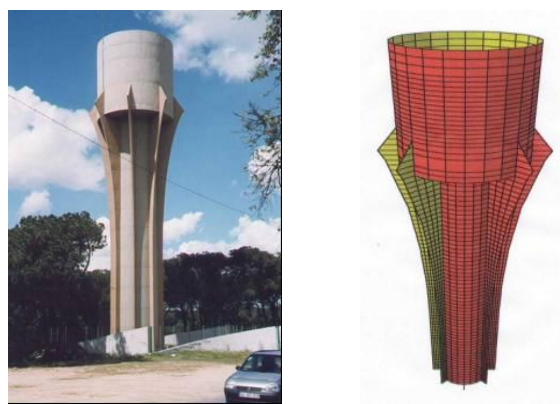

\begin{tabular}{|c|c|c|}
\hline Modes & $\begin{array}{c}\text { Analytical } \\
\mathbf{f}(\mathbf{H z})\end{array}$ & $\begin{array}{c}\text { in-situ Testing } \\
\mathbf{f}(\mathbf{H z})\end{array}$ \\
\hline $\mathbf{1 X}$ & 1.23 & 1.25 \\
$\mathbf{1 Y}$ & 1.23 & 1.35 \\
$\mathbf{T}$ & 5.96 & 6.38 \\
$\mathbf{2 X}$ & 10.33 & 9.80 \\
$\mathbf{2 Y}$ & 10.33 & 9.80 \\
\hline
\end{tabular}

Cavaquinhas - RC shell with strong columns (Type 4)

Fig. 6. Comparison between the analytical and in-situ testing frequencies. (The standard deviation of the analytical model is zero because materials and geometry are treated as deterministic; for the in-situ testing, the standard deviation is on the order of $0.05 \mathrm{~Hz}$ depending on the uncertainty of the water level).

The results are remarkably similar, indicating that the analytical model can reproduce the real structure in the linear range, and the model can subsequently be used in the nonlinear study, including vulnerability analysis.

For the Miratejo water tank, the in-situ testing was more complete using three stations along the height of the structure, allowing the shapes of the first modes in the $\mathrm{x}$ and $\mathrm{y}$ directions and the damping ratio to be identified. In Fig. 7, the results obtained in the analytical model were compared with the results obtained by applying diverse identification techniques (curve fitting and Power Spectral Density, PSD, rms of one-degree-of-freedom oscillator transfer function) [28].

For the fundamental frequencies, the agreement is very good. However, the analytical model for the second mode shape is very different from the observed one (depending very much on the identification technique used), requiring further analysis in both the modeling and the identification technique, for which better fitting for the high-degree modal shapes and damping ratios are needed. These studies should involve working with other structures and using more sophisticated identification techniques, such as frequency domain decomposition (FDD), enhanced frequency domain decomposition (EFDD), or stochastic subspace identification (SSI) [29]. As far as damping ratio is concerned, the average value obtained through the transfer function fitting was on the order of $1 \%$. 

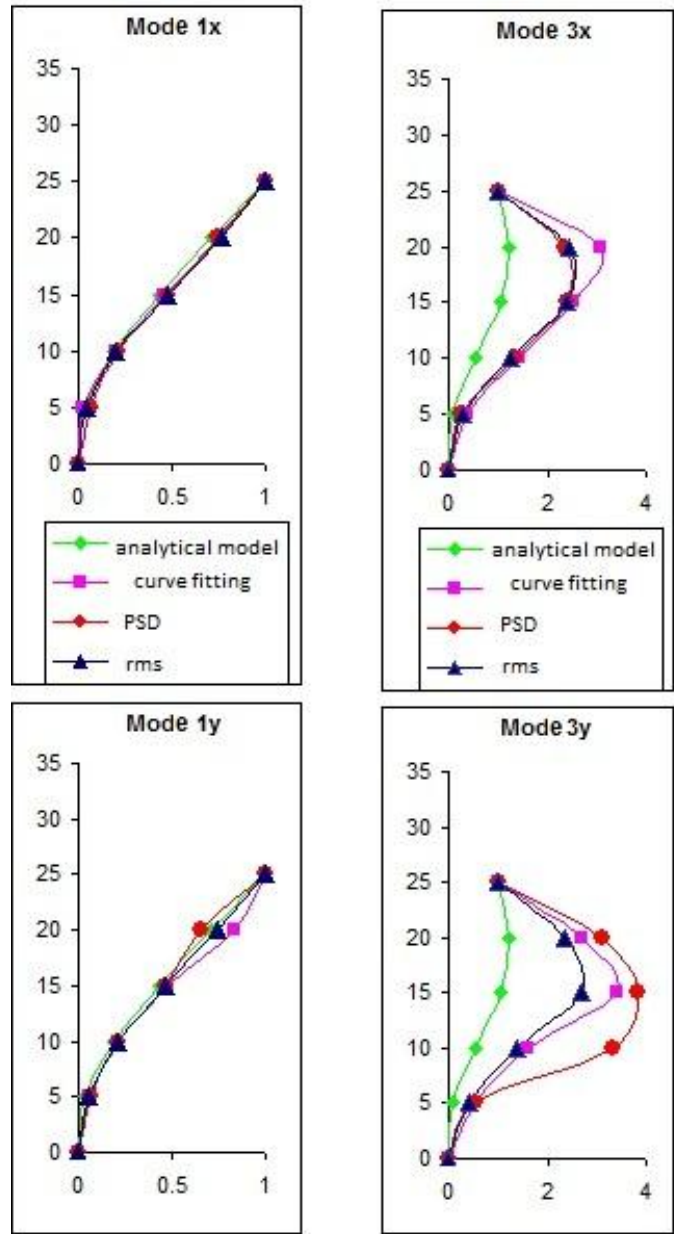

Fig. 7. Comparison among various methods used to determine the 1 st and 2 nd modes of translation (1 and 3 ) for the $\mathrm{x}$ and $\mathrm{y}$ directions.

The consistent disagreement (30\% or more) between the in-situ and the numerical modeling frequency results found when performing a similar analysis for buildings (see [30]) is due to the great uncertainties in the elastic properties of several elements of those structures as well as the boundary conditions created by adjacent buildings. The interaction of buildings in urban blocks, the existence of non-structural elements, such as infill walls, and the uncertainties in modeling are among the most critical issues when dealing with building frequencies. However, if modeling considers all structural and non-structural elements, the agreement is much better.

The elevated water tanks like the ones in this study are composed by more standard structures and, consequently, the results from modeling are much better than with building.

\section{Estimating the natural frequency of elevated water tanks}

An empirical formula to compute the fundamental frequency of an RC-elevated water tank would be very useful for a designer to quickly assess its response to ground motion.

The simplest idea would be to relate frequency or period of first mode with one single parameter characterizing the RC tank. In buildings the height is the parameter used in all codes and studies [30].

Figure 4 was made based on this idea. In Fig. 4a all typologies were treated together and the dispersion is very large. One realizes that it is impossible to mix very different structural typologies, such as space frames and shafts. If 
grouped by typologies, as represented in Fig. 4b, the results become much better with higher correlation value between frequencies and heights. Based on these results future work may reduce the total number of typologies considered in here to a smaller number.

An additional analysis was made to estimate more adequately the fundamental frequency of vibration of these structures. Based on the data collected, a simple formula was developed knowing the equivalent inertia of the cross section of a hypothetical shaft, the mass of tank with water, and the height of the tank.

According to Clough and Penzien [31], the first frequency of vibration $(f)$ for a cantilever (with continuous mass and inertia) is given by Eq. (1) or Eq. (2) for the case of a concentrated mass $m$ at the top of a mass-less cantilever:

$$
\begin{aligned}
& f=\frac{1}{2 \pi} \cdot 1.875^{2} \sqrt{\frac{E I}{\bar{m} L^{4}}} \\
& f=\frac{1}{2 \pi} \sqrt{\frac{3 E I}{m L^{3}}}
\end{aligned}
$$

where $E$ is the modulus of elasticity, $I$ is the second moment of the cross section, $\bar{m}(=\rho \times A)$ is the mass per unit of length and $L$ is the total height of the cantilever (with $\rho$ and $A$ being the mass density and the area of the cross section, respectively). Therefore, the fundamental frequency of the tank is expected to be a function of the second moment of area and the height of the tank. $E$ and $\rho$ are material properties.

The height of the tank $H$, which is relevant for the first frequency of vibration, was given by the length of the shaft from the ground to the center of gravity of the tank with water. Based upon these parameters, a new equation (Eq. (3)) was developed to account for this parameterization.

$$
f=\alpha \cdot M_{(\text {tank }+ \text { water })}^{\beta} \cdot I_{e}^{\gamma} \cdot H^{\delta}
$$

where $M$ is the mass of the tank with water, and $I_{e}$ is the equivalent inertia of the cross section of a shaft. $\alpha, \beta, \gamma$, and $\delta$ are parameters to obtain from data fitting. For the structures analyzed in this work, the value of $I$ was obtained by applying a force at the top of the structure in the analytical model and determining the corresponding horizontal displacement. Using the mean square regression analysis, the constants were computed: $\alpha=476.28, \beta=-0.2972$, $\gamma=0.2782$, and $\delta=-1.4572$. These values were determined through an iterative process that minimizes the difference between the experimental results and the empirical equation.

In Fig. 8, the results obtained with Eq. (3) and the in-situ experimental values are compared for the 6 cases studied in detail.

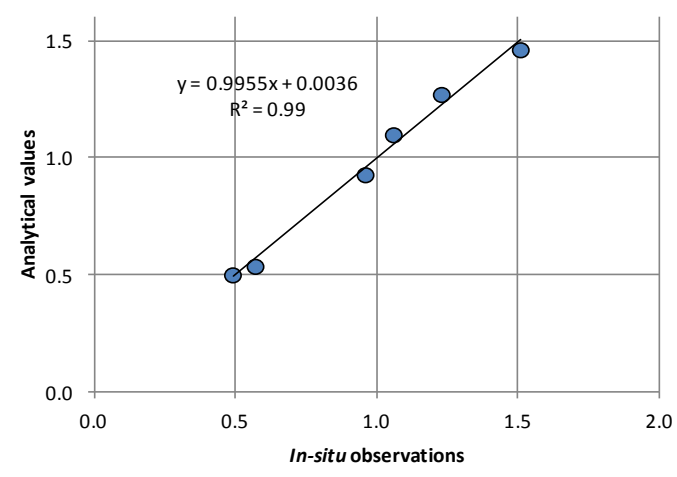

\begin{tabular}{|c|c|c|c|}
\hline $\mathrm{Hz}$ (in situ) & $\mathrm{M}$ (ton) & $\mathrm{I}(\mathrm{m} 4)$ & $\mathrm{H}(\mathrm{m})$ \\
\hline 0.49 & 164 & 0.23 & 29.41 \\
\hline 1.51 & 250 & 5.48 & 23.76 \\
\hline 1.23 & 400 & 5.48 & 23.76 \\
\hline 0.96 & 643 & 16.48 & 33 \\
\hline 1.06 & 365 & 16.48 & 33 \\
\hline 0.57 & 654 & 5.311 & 38.5 \\
\hline
\end{tabular}

Fig. 8. 1st Mode - analytical frequencies vs. in-situ frequencies.

The results presented in Fig. 8 show a good match between analytical and in-situ frequencies of the 1 st mode. The extension of formulae (Eq. (3)) to other situations requires further studies including the analysis of a larger number of tanks, possibly leading to more robust values of the fitting parameters. 


\section{Conclusions and final considerations}

The main conclusions from this work can be summarized as follows:

- A large set of RC-elevated water tanks (44 tanks), covering the most common types and sizes existing in Portugal, were studied and characterized in terms of geometry and frequency of vibration. Similar tanks are in still in function in many countries.

- In-situ measurements with ambient noise led to the identification of the first frequencies of vibration of various types of water tanks. Generally, up to 4 modes in one direction including the first torsion mode could be identified. This was performed with a single 3 -component accelerometric station. A damping ratio on the order of $1.0 \%$ was obtained for several structures.

- The finite element analytical models developed for a group of 6 structures covering 3 different typologies reproduce the results of the in-situ testing with great accuracy in terms of frequencies of several modes. However, in terms of modal shapes, only the 1st modes ( $\mathrm{x}$ and $\mathrm{y}$ ) were reproduced adequately. Further studies are needed to improve the modal shape fitting at higher frequencies by introducing slight corrections on the structural modeling and using more sophisticated identification techniques [29].

- For several tanks, it was possible to obtain an expression to compute the 1 st frequency based on the mass at the top of the structure, the inertia, and the height of the supporting structure. Extension of this expression to other situations should be the object of future work.

- This study, although based on small amplitude vibration, provides critical information on frequencies and structural modeling of RC elevated water tanks which is of most relevance for their analysis and design.

The effect of sloshing of water and the effect of the nonlinear behavior of structural materials on frequencies of vibration for larger amplitude motions is outside the scope of this paper, but should be analyzed in the future.

This work can be applied to study seismic vulnerability, such as the one conducted in [4], using pushover analysis [32], and address structural safety.

\section{Acknowledgments}

CSO acknowledges the partial financial support given by Fundação para a Ciência e a Tecnologia, Portugal (FCT) through its Pluri-Annual Programme. The suggestions made by three anonymous reviewers are greatly acknowledged.

\section{References}

[1] C.S. Oliveira, J.J. Azevedo, R. Delgado, A.G. Costa and A.C. Costa, O Sismo de Northridge Los Angeles, 17 de Janeiro de 1994 Ensinamentos para Portugal, 1995. (in portuguese)

[2] RSA, Regulamento de Segurança e Acções para Estruturas de Edifícios e Pontes, Decreto-Lei n. ${ }^{\circ} 235 / 83$, de 31 de Maio, Imprensa Nacional, Lisboa, 1983. (in portuguese)

[3] E.C. Carvalho, C.S. Oliveira, A. Campos-Costa and M.L. Sousa, Definição da Acção Sísmica no âmbito do Documento Nacional de Aplicação (DNA) do EC-8, Proceedings Sísmica-1999, Faro, 1999. (in portuguese)

[4] H.M. Lopes and C.S. Oliveira, Use of in-situ Dynamic Measurements to Calibrate Analytical Models of RC Elevated Water Tanks and to Assess their Seismic Vulnerability, Proceedings, ICEDyn2011, 2011.

[5] C.S. Oliveira, A.R. Lucas and J.H. Correia Guedes, Monografia, 10 Anos após o Sismo dos Açores de 1 de Janeiro de 1980, volums 1 and 2, Lisboa, 1992. (in portuguese)

[6] J.E. Hurtado Alva, López and D. Vásques, Nasca Earthquake, November 12, 1996, Peru. (Personal Communication)

[7] M. Mermari, M.M. Ahmadi and B. Rezae, Behavior of Reinforced Concrete Water Towers During the Manjil-Roudbar Earthquake of June 1990, Proceedings, 10th World Conference on Earthquake Engineering, Balkema, 1992.

[8] Friuli earthquake, 1976: Performance of a Railway Water Tank, Courtesy A. Lopez-Arroyo, 2007.

[9] D.C. Rai, Performance of Elevated Tanks in Mw7.7 Bhuj Earthquake of January 26, 2001, Proceedings Indian Academy Science (Earth Planet Sciences) 112(3) (2003), 421-429.

[10] "Haiti earthquake, 2010: Performance of a Port-au-Prince Water Tank" (Courtesy C. S. Oliveira), 2010.

[11] A. Costa, C.S. Oliveira and M.A. Ferreira, The Sichuan Earthquake of 2008 and the Performance of main Structural Systems, (in preparation), 2012.

[12] G.W. Housner, The dynamic behavior of water tanks, Bulletin of Seismological Society of America 53 (1963), 381-387. 
[13] BIS, IS:11682, Criteria for Design of RC Staging for Overhead Water Tanks, New Delhi, 1985.

[14] M.J.N. Priestley, B.J. Davidson, G.D. Honey, D.C. Hopkins, R.J. Martin, G. Ramsey, J.V. Vessey and J.H. Wood, Seismic Design of Storage Tanks: Recommendations of a Study Group of the New Zealand National Society of Earthquake Engineering, 1986.

[15] IS:13920, Ductile Detailing of Reinforced Concrete Structures Subjected to Seismic Forces.- Code of Practice, Bureau of Indian Standards, New Delhi, 1993.

[16] ACI-371-R98, Guide for Analysis, Design, and Construction of Concrete-Pedestal Water Tanks, Farmington Hills, MI, 1998.

[17] IBC 2000, International Building Code, International Conference of Building Officials, Whittier, CA, 2000.

[18] EC8, Eurocode 8, Design of structures for earthquake resistance - Part 6: Towers, masts and chimneys, EN 1998 Brussels, 2005.

[19] IITK-GSDMA, Guidelines for Seismic Design of Liquid Storage Tanks, Indian Institute of Technology, NICEE, Kanpur, 2005.

[20] D.C. Rai, Seismic retrofitting of RC shaft support of elevated tanks, Earthquake Spectra 18(4) (2002), 745-760.

[21] D.C. Rai, Review Code for Design Forces for Shaft Support of Elevated Tanks, Proceedings of 12th Symposium on Earthquake Engineering, IIT, Roorkee, 2002, pp. 1407-1418.

[22] A.R. Chandrasekaran and J. Krishna, Water Towers in Seismic Zones, Proceedings 3rd World Conference on Earthquake Engineering, New Zealand, IV, 1965, pp. 161-171.

[23] W.H. Boyce, Vibration Tests on a simple Water Tower, Proceedings 5th World Conference on Earthquake Engineering, Italy, I, 1974, pp. 220-225.

[24] C.S. Oliveira, E. Çaktı, D. Stengel and M. Branco, Minaret behavior under earthquake loading: The case of historical istanbul, Earthquake Engineering and Structural Dynamics (2011), Published online in Wiley Online Library (wileyonlinelibrary.com). DOI: 10.1002/ eqe. 1115 .

[25] RSCS, Regulamento de Segurança das Construções Contra os Sismos, Imprensa Nacional, Lisboa, 1958. (in portuguese)

[26] RSEP, Regulamento de Solicitações em Edifícios e Pontes, Imprensa Nacional, 1961. (in portuguese)

[27] SAP2000®, Integrated Software for Structural Analysis and Design, Computers and Structures, Inc: CA, 2008.

[28] H. Lopes, P. Ferreira, J.M. Proença and C.S. Oliveira, Modelação Sísmica de um Reservatório Elevado no Seixal, Proceedings, Sísmica-2001, Ponta Delgada, Azores, 2001. (in portuguese)

[29] ARTeMIS Extractor ${ }^{\circledR}$, Ambient Response Testing and Model Identification Software, Structural Vibration Solutions”, A/S, 2009.

[30] C.S. Oliveira and M. Navarro, Fundamental periods of vibration of RC buildings in portugal from in-situ experimental and numerical techniques, Bulletin of Earthquake Engineering 8(3) (2010), 609-642. (DOI 10.1007/s10518-009-9162-1)

[31] R. Clough and J. Penzien, Dynamics of Structures, McGraw-Hill: U.S.A., 1975.

[32] Applied Technology Council, ATC 40, Seismic Evaluation and Retrofit of Concrete Buildings, Redwood City, California, 1996. 

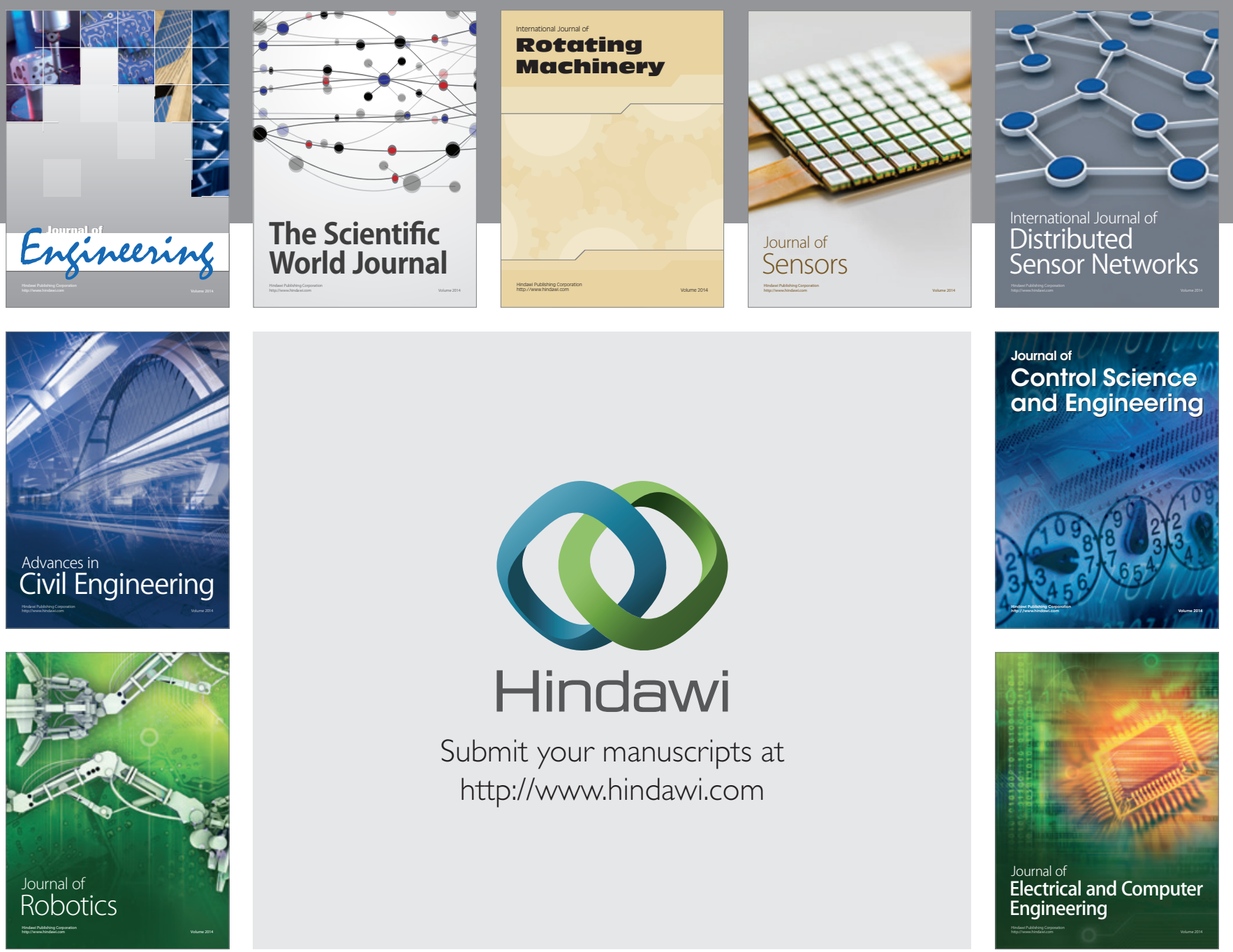

Submit your manuscripts at

http://www.hindawi.com
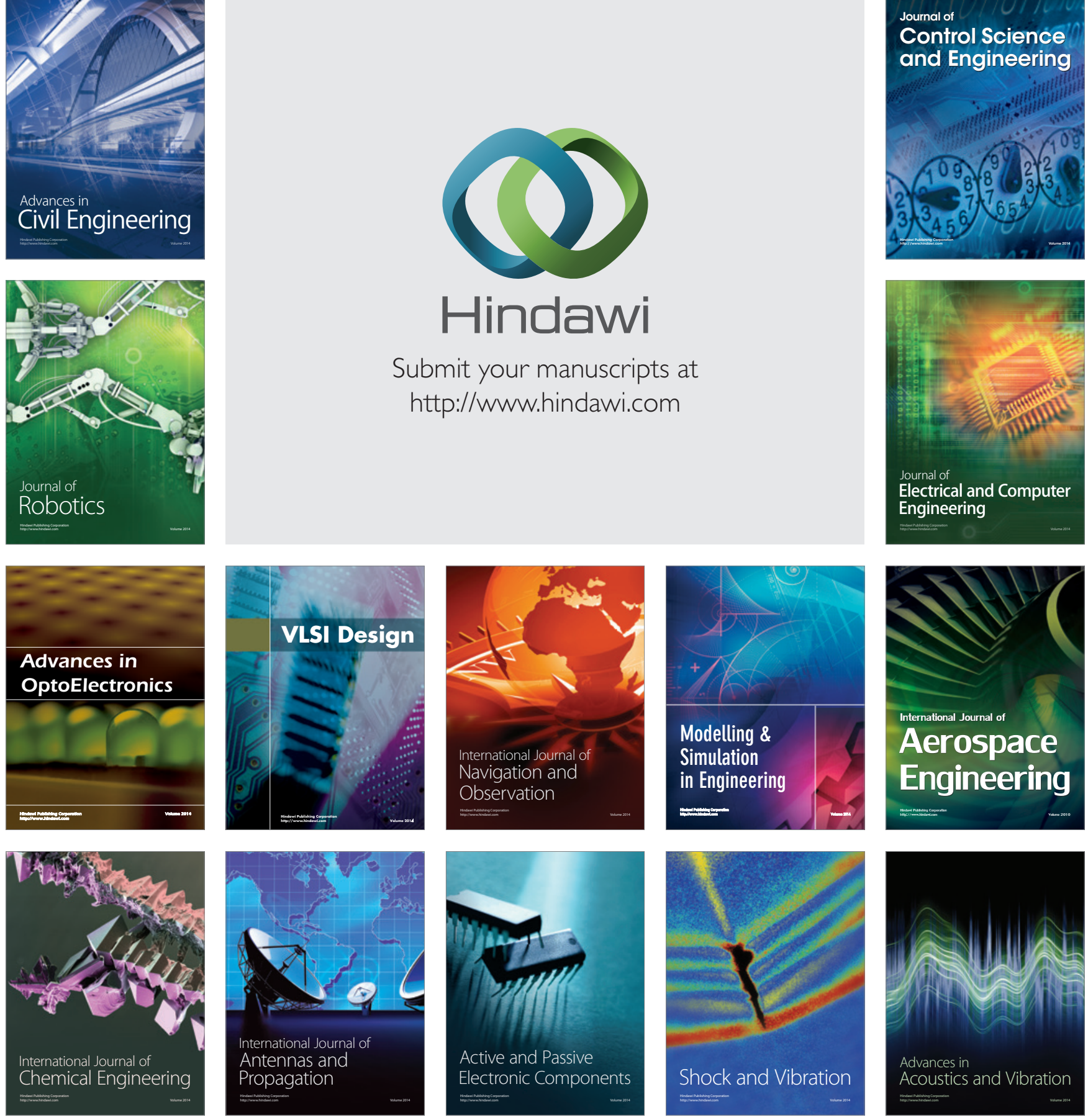